\title{
Optimization of the extraction of antioxidants and caffeine from maté (Ilex paraguariensis) leaves by response surface methodology
}

\author{
Hartwig, Vanessa G..$^{a^{*}}$, Schmalko, Miguel E. ${ }^{a}$, Alzamora, Stella M. ${ }^{b}$, And \\ Brumovsky, Luis A. ${ }^{a}$ \\ ${ }^{a}$ Faculty of Exact, Chemistry and Life Sciences, National University of Misiones, Posadas, Argentina \\ ${ }^{\mathrm{b}}$ Industry Department, Faculty of Exact and Natural Sciences, University of Buenos Aires, Argentina \\ ${ }^{*}$ Corresponding author \\ vanesshart@yahoo.com.ar \\ TEL: (+54) 0376-435099 \\ FAX: $(+54)$ 0376-4425414
}

Received: 22 June 2012; Published online: 18 April 2013

\begin{abstract}
Optimal conditions for the industrial extraction of total polyphenols from maté (Ilex paraguariensis) were determined using response surface methodology, with two independent variables: ethanol percentage of the extraction solution and liquid to solid ratio. Response variables were total polyphenol content, antioxidant capacity, concentration of total polyphenols and caffeine content.

The optimal conditions found were a liquid to solid ratio from $8-9 \mathrm{w} \mathrm{w}^{-1}$ and ethanol percentage of the extraction solution from $30-50 \% \mathrm{w} \mathrm{w}^{-1}$. Under these conditions the main predicted values corresponding to leaf extracts were $40 \mu \mathrm{g}$ chlorogenic acid equivalents $\mathrm{mL}^{-1}$ of original extract, $13 \mathrm{~g}$ chlorogenic acid equivalents per $100 \mathrm{~g}$ dry matter for total polyphenol content, $22 \mathrm{~g}$ Trolox equivalents and $15.5 \mathrm{~g}$ ascorbic acid equivalents per $100 \mathrm{~g}$ dry matter for antioxidant capacity. The total polyphenol content of twig extracts was $36 \%$ lower than that in the leaf extracts.
\end{abstract}

Keywords: Extraction; optimization; Ilex paraguariensis; polyphenols; antioxidant capacity 
$70 \mid$ Hartwig et al.

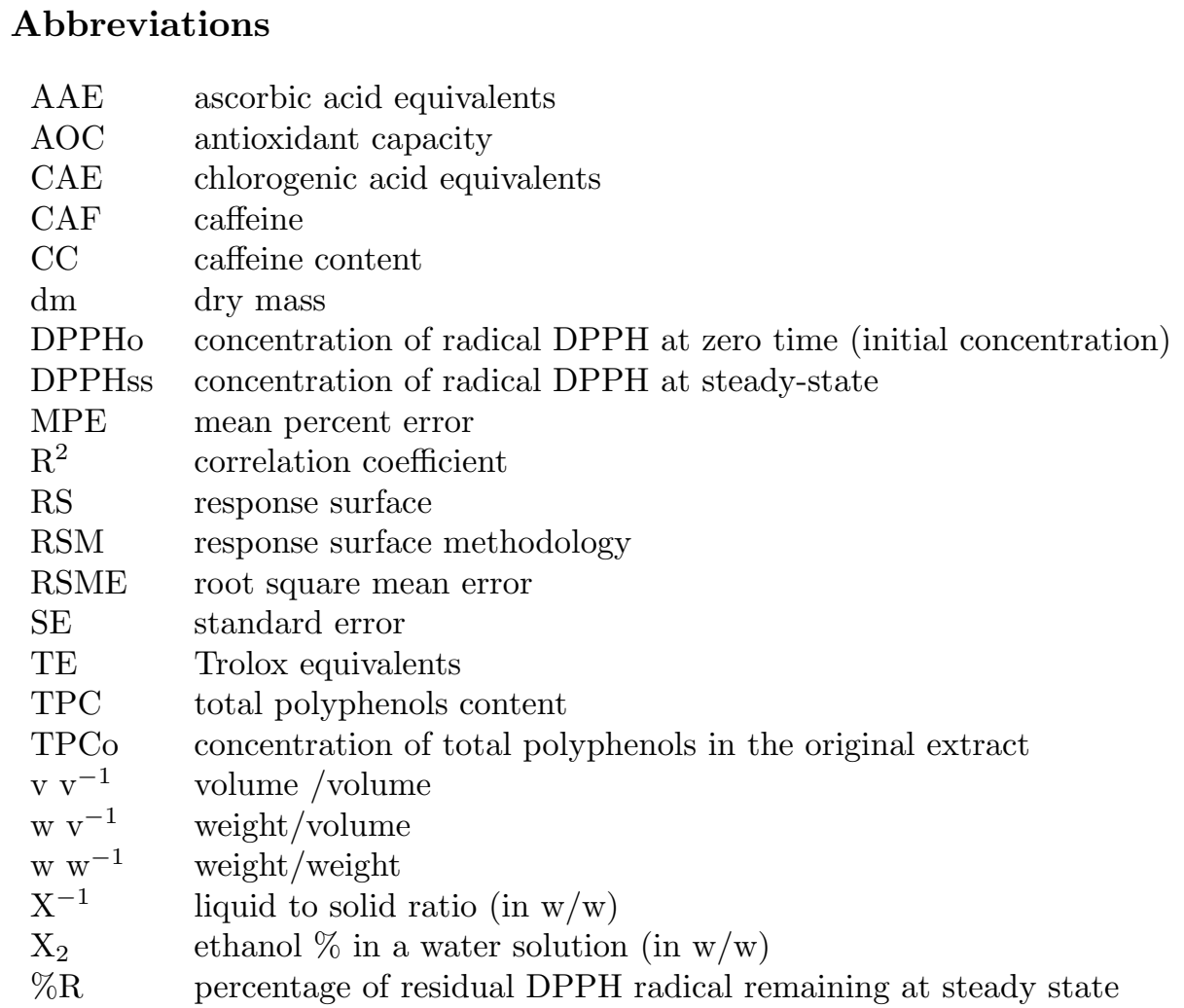

\section{Introduction}

Yerba maté (or maté tea) is a widely consumed infusion in some countries of South America. It is obtained from leaves and twigs of the Ilex paraguariensis tree. Processing steps comprise heat treatment, drying, seasoning and grinding. In recent years, maté tea has been introduced to markets in Arabia, Europe and the United States. Increasing demand is probably due to the presence of xanthines and phenolic compounds. Several studies on maté have reported the presence of xanthines such as caffeine and theobromine, saponines, and several phenolic compounds, like chlorogenic acids and dicaffeoylquinic acid derivatives (Bravo, Goya, \& Lecumberri, 2007; Filip, Lotito, Ferraro, \& Fraga, 2000; Ramallo, Lovera, \& Schmalko, 2010). The presence of caffeine in maté has been known since 1940 and it was widely studied in the last century. In recent years many researchers have studied phenolic compounds in maté. The presence of polyphenolic compounds gives the extract an in vitro antioxidant capacity (AOC) equal to or higher than that of ascorbic acid and vitamin E (Filip et al., 2000). Dudonné, Vitrac, Coutiere, Woillez, and Merillon (2009) ranked the antioxidant capacity of aqueous extracts of maté as fifth highest out of 30 plants.

Extraction of polyphenols is influenced by extraction temperature (Wettasinghe \& Shahidi, 1999), solvent polarity (Turkmen, Sari, \& Velioglu, 2006), liquid/solid ratio (Cacace \& Mazza, 2003) and other factors. Due to presence of different polyphenols in different plants, optimal extraction conditions vary between plants. For example, Yao et al. (2006) found that methanol was more effective than water for extraction of tea polyphenols, whilst Zhou and Yu (2004) obtained the best results using a $50 \% \mathrm{v} \mathrm{v}^{-1}$ acetone/water mixture for extraction of wheat polyphenols. Nevertheless, Khokhar and Magnusdottir (2002) found water to be more effective for extraction of tea cathechins than $80 \% \mathrm{v} \mathrm{v}^{-1}$ methanol/water and $70 \% \mathrm{v} \mathrm{v}^{-1}$ ethanol/water solvents. In addition, Hayouni, Abedrabba, Bouix, and Hamdi (2007) reported that water and organic sol- 
vents used individually or in mixtures, such as acetone:water:acetic acid (90:9.5:0.5) and ethylacetate:methanol:water (60:30:10), significantly affected the total polyphenol contents of Quercus coccifera L. and Juniperus phoenicea L. fruit extracts.

Ethanol-water mixtures were found to be suitable for extraction of total polyphenols from plant tissues with variable polyphenolic composition, including milled soybeans (Jokić et al., 2010), black and green tea (Astill, Birch, Dacombe, Humphrey, \& Martin, 2001; Sairro et al., 2007), black currants (Cacace \& Mazza, 2003), apple pomace (Wijngaard \& Brunton, 2010), red fruit by-products (Lapornik, Prosek, \& Wondra, 2005), and jabuticaba skins (Santos, Veggi, \& Meireles, 2012).

Spigno, Trarnelli, and De Faveri (2007) found that a high concentration of water in ethanolwater mixtures (below 50\%) reduced the extraction of polyphenols from grapes. Also, Rostagno, Palma, and Barroso (2004) found that it was necessary to add water (30-40\%) in order to improve the extraction of phenolic compounds from soybeans, but above $60 \%$ added water the extraction effectiveness diminished.

Many solvents have been used to extract polyphenols from maté leaves: water, methanol, acetone, ethanol and water-ethanol mixtures (Dudonné et al., 2009; Pineda Rivelli et al., 2007; Turkmen et al., 2006). However, the researchers have reached different conclusions on the best extraction solvent for maté leaves.

Turkmen et al. (2006) concluded that an ethanolwater mixture $\left(50 \% \mathrm{v} \mathrm{v}^{-1}\right)$ was better than a methanol-water mixture $\left(50 \% \mathrm{v} \mathrm{v}^{-1}\right)$ at room temperature.

Pagliosa et al. (2010) compared water and a methanol-water mixture (80:20 in volume) for extraction of polyphenols (at $85^{\circ} \mathrm{C}$ ) in maté leaves and twigs. They found a better extraction from leaves using water, and from twigs using a methanol-water mixture. They concluded that polyphenols in maté leaves and twigs were different.

Turkmen et al. (2006) studied the effects of water and different organic solvents (acetone, ethanol and methanol at 50\%, $80 \%$ and $100 \% \mathrm{v}$ $\mathrm{v}^{-1}$ ) on the extraction of polyphenols and AOC from maté leaves. All extracts prepared with a solvent-water mixture $\left(50 \% \mathrm{v} \mathrm{v}^{-1}\right)$ had the highest levels of polyphenols. The lowest amounts of polyphenols were obtained using $100 \%$ acetone or 100\% ethanol. Turkmen et al. (2006) concluded that solvent polarity increased the extraction of polyphenols. In this research, the optimization of extraction applied to industrial maté processing thus methanol could not be used due to its toxicity. Furthermore, the solvent to solid ratio was fixed at low values in order to reduce the amount of solvent that had to be removed in downstream unit processes (evaporation and drying). In the work of other researchers (Spigno et al., 2007; Rostagno et al., 2004; Pagliosa et al., 2010), the solvent to solid ratio was relatively high.

Sambiassi, Escalada, and Schmalko (2002) studied water extraction of soluble compounds from maté and concluded that the best results were obtained with a water to solid ratio between 8 and $11.4 \mathrm{~g}$ of water (g of dry solid) ${ }^{-1}$.

Response surface methodology (RSM) is a useful tool for optimization of extraction operations. It has been used by many researchers to optimize the extraction of polyphenols from apple pomace (Wijngaard \& Brunton, 2010) and other materials. In all those studies, as in this research, solvent concentration, at different levels, was used as one of the independent variables.

The overall aim of this research is to optimize the extraction of polyphenols, with a high in vitro antioxidant activity, from maté leaves. The first objective was to optimise extraction, using the RSM, with ethanol concentration in the extraction solution and solvent to solid ratio as independent variables, and antioxidant capacity, polyphenols content and caffeine content as the dependent variables. A second objective, was to compare the recovery of polyphenols using pure water and ethanol $\left(96 \% \mathrm{v} \mathrm{v}^{-1}\right)$ as extraction solvents, near their respective boiling points.

\section{Materials and Methods}

\section{$2.1 \quad$ Reagents}

For extraction of polyphenols, distilled water, ethanol $96^{\underline{0}}$ and methanol (Merck Química, HPLC grade, Argentina) were used. The total polyphenols content (TPC) was determined us- 
ing Folin-Ciocalteu's phenol reagent (Fluka, Argentina), chlorogenic acid (MP Biomedicals, Argentina), anhydrous sodium carbonate (99\% purity, Anedra Argentina) and methanol (Merck Química, HPLC grade, Argentina). For the determination of AOC, DPPH (1,1-diphenyl2-picrylhydrazyl radical, Sigma Aldrich, Argentina), ascorbic acid (Sigma Ultra, Argentina), Trolox (6-hydroxy-2.5.7.8-tetramethylchroman2-carboxilic acid; Sigma Aldrich, Argentina) and methanol (Merck Química, HPLC grade, Argentina) were used. Caffeine (Sigma Ultra, Argentina) and methanol (Merck Química, HPLC grade, Argentina) were used in the determination of caffeine content (CC).

\section{$2.2 \quad$ Materials}

Coarse ground maté samples were purchased from a local industrial supplier in Apostoles, Argentina. Twigs were manually separated from leaves. Each fraction was ground and sieved, and the fraction that passed a 40-mesh sieve was used. Twigs were only used for comparing the TPC of each fraction.

\subsection{Equipment}

Absorbance measurements were made using a spectrophotometer UV-Vis (Spectrum SP-2102, photometric accuracy $0.3 \% \mathrm{~T}$, spectrum band width: $2 \mathrm{~nm}$ ). All samples were analyzed in 10 mm quartz cells at room temperature.

\subsection{Experimental design and data analysis}

A central composite design was used to determine the optimal extraction conditions. Two factors were used as independent variables: liquid to solid ratio $\left(X_{1}, \mathrm{w} \mathrm{w}^{-1}\right)$ and ethanol percentage of the extraction solution $\left(X_{2}, \mathrm{w} \mathrm{w}^{-1}\right)$. The response variables were: total polyphenols content (TPC), caffeine content (CC), antioxidant capacity (AOC) and concentration of total polyphenols (TPCo).

All the experiments were conducted in duplicate. The coded levels of the independent variables were determined using equation 1.

$$
x i=(X i-X i o) / \Delta x i
$$

where $\mathrm{xi}$ is the coded value; $\mathrm{Xi}$ is the uncoded value of the ith test variable; Xio is the uncoded value of the $i$ th test variable at center point and $\Delta \mathrm{xi}$ is the factor increment.

The experimental design is shown in Table 1. To estimate the response equation, a regression analysis was performed using a second order polynomial (eq. 2):

$$
\begin{array}{r}
y=a_{0}+a_{1} X_{1}+a_{2} X_{2}+a_{11} X_{1}^{2} \ldots \\
\ldots+a_{22} X_{2}^{2}+a_{12} X_{1} X_{2}
\end{array}
$$

where $y$ is the response variable; $\mathrm{a}_{0}, \mathrm{a}_{1}, \mathrm{a}_{2}, \mathrm{a}_{11}$, $\mathrm{a}_{22}$ and $\mathrm{a}_{12}$ are the estimated coefficients, and $X_{1}$ and $X_{2}$ are the uncoded independent variables.

The strength of the fit was determined using four statistical parameters: the determination coefficient $\left(\mathrm{R}^{2}\right)$, the Chi-square value $(\chi 2$, eq. 3$)$, the root square mean error (RSME, eq. 4) and the mean percent error (MPE, eq. 5). The $\mathrm{R}^{2}$ values provide the percentage of the variation explained by the model. The $\chi 2$ value takes into account the differences between experimental (exp) and predicted (pre) data, the number of experimental data points $(\mathrm{N})$ and the number of parameters $(\mathrm{Np})$ used in the model $(\mathrm{N}-\mathrm{Np}$, or degrees of freedom). The RMSE was expressed as the mean absolute difference between the experimental and predicted data, whereas the MPE is related to the relative difference.

$$
\text { Chi square }\left(\chi^{2}\right)=\frac{\sum\left(Y_{e x p}-Y_{p r e}\right)^{2}}{N-N p}
$$

Root mean square error (RMSE) $=$

$$
\left[\frac{1}{n} \sum\left(Y_{e x p}-Y_{p r e}\right)^{2}\right]^{0.5}
$$

Meanpercent error $(\mathrm{MPE})=$

$$
\frac{100}{N} \sum \frac{\left|Y_{e x p}-Y_{p r e}\right|}{Y_{e x p}}
$$

\subsection{Preliminary extraction experiments}

Two preliminary experiments were conducted in order to determine the TPC in twigs and leaves 
Polyphenol extraction from maté $\mid 73$

Table 1: Response surface design and corresponding response experimental values for extraction of maté leaves with $\mathrm{X}_{1}$ (liquid to solid ratio, in $\mathrm{g}$ liquid/g dry solid) and $\mathrm{X}_{2}$ (ethanol concentration, in \% w/w) as independent variables and TPCo: Concentration of total polyphenols, TPC: Total polyphenols content, CC: Caffeine content and AOC: antioxidant capacity as dependent variables

\begin{tabular}{c|cc|ccccc}
\hline $\begin{array}{c}\text { Expe- } \\
\text { riment }\end{array}$ & \multicolumn{2}{|c|}{$\begin{array}{c}\text { Independent } \\
\text { variable }\end{array}$} & \multicolumn{5}{c}{ Responses } \\
\hline & $\mathbf{X}_{1}\left(\mathbf{x}_{1}\right)$ & $\mathbf{X}_{2}\left(\mathbf{x}_{2}\right)$ & TPCo & TPC & CC & AOC-TE & AOC-AAE \\
\hline 3 & $6(-1)$ & $25(-1)$ & $37.9 \pm 2.10^{a, c}$ & $11.0 \pm 0.00^{a}$ & $0.34 \pm 0.02^{a, b}$ & $18.6 \pm 0.07^{a, d}$ & $13.2 \pm 0.05^{a, b}$ \\
4 & $6(-1)$ & $75(1)$ & $41.5 \pm 2.04^{b, c}$ & $8.2 \pm 0.15^{d}$ & $0.35 \pm 0.01^{a, b, c}$ & $14.1 \pm 0.35^{e}$ & $10 \pm 0.26^{e}$ \\
5 & $10(1)$ & $25(-1)$ & $34.8 \pm 0.06^{a, d}$ & $13.4 \pm 0.40^{b}$ & $0.45 \pm 0.02^{e}$ & $21.8 \pm 1.49^{b, c}$ & $15.5 \pm 1.04^{c, d}$ \\
6 & $10(1)$ & $75(1)$ & $23.5 \pm 1.27^{f}$ & $9.7 \pm 0.60^{c}$ & $0.37 \pm 0.01^{d, e}$ & $14.3 \pm 1.12^{e}$ & $10.1 \pm 0.79^{e}$ \\
7 & $10.82(1.41)$ & $50(0)$ & $29.0 \pm 1.00^{e}$ & $12.8 \pm 0.20^{b}$ & $0.43 \pm 0.01^{b, c, d}$ & $23.1 \pm 0.46^{b}$ & $16.4 \pm 0.35^{d}$ \\
8 & $5.18(-1.41)$ & $50(0)$ & $31.7 \pm 1.19^{d, e}$ & $9.6 \pm 0.00^{c}$ & $0.29 \pm 0.01^{a}$ & $17.2 \pm 1.01^{d}$ & $12.2 \pm 0.7^{a}$ \\
9 & $8(0)$ & $85.25(1.41)$ & $21.6 \pm 0.73^{f}$ & $7.0 \pm 0.15^{d}$ & $0.41 \pm 0.01^{c, d, e}$ & $12.8 \pm 0.01^{e}$ & $9.1 \pm 0.01^{e}$ \\
10 & $8(0)$ & $14.75(-1.41)$ & $36.2 \pm 1.27^{a, d}$ & $10.0 \pm 0.25^{a, c}$ & $0.35 \pm 0.01^{a, b, c}$ & $21 \pm 1.76^{a, c}$ & $14.9 \pm 1.23^{b, c}$ \\
11 & $8(0)$ & $50(0)$ & $42.96 \pm 0.89^{b}$ & $12.7 \pm 0.27^{b}$ & $0.42 \pm 0.01^{d, e}$ & $22.2 \pm 0.45^{b}$ & $15.7 \pm 0.32^{d}$ \\
\hline
\end{tabular}

Data are expressed as means \pm SE. Values bearing different letters are significantly different at $\mathrm{p} \leq 0.012$. CAE: chlorogenic acid equivalent; TE: Trolox equivalents; AAE: ascorbic acid equivalents. TPCo (g CAE/100 mL); TPC (g CAE \%dm); $\mathrm{CC}(\mathrm{g} \mathrm{CAF} \% \mathrm{dm})$; AOC (g standard equivalents \% dm)

of maté and the extraction time. In the first one, the extracts from both materials were obtained according to the method described in the standard ISO/FDIS 14502-1:2004 (2004) (Experiment 1). In this method, $0.200 \pm 0.001 \mathrm{~g}$ of each sample was weighed in an extraction tube, and $5 \mathrm{~mL}$ of methanol $\left(70 \% \mathrm{v} \mathrm{v}^{-1}\right)$ at $70{ }^{\circ} \mathrm{C}$ was added. The extract was mixed, shaken and heated at $70{ }^{\circ} \mathrm{C}$ for $10 \mathrm{~min}$. After cooling at room temperature, the extract was centrifuged for $10 \mathrm{~min}$ and the supernatant was decanted into a graduated tube. The extraction step was repeated twice. Both extracts were pooled and the volume adjusted to $10 \mathrm{~mL}$ with cold methanol $\left(70 \% \mathrm{v} \mathrm{v}^{-1}\right)$. One $\mathrm{mL}$ of the extract was diluted into water to $100 \mathrm{~mL}$. Three independent extractions were carried out in duplicate for each maté fraction. The second experiment was carried out to determine the extraction time to be used in the experimental design (Experiment 2). Thirty $\pm 0.001 \mathrm{~g}$ dry matter $(\mathrm{dm})$ of maté leaves were transferred to a $500 \mathrm{~mL}$ sealed Erlenmeyer flask, and $240 \pm 1 \mathrm{~g}$ of water at $60 \pm 2^{\circ} \mathrm{C}$ was added. The flask was kept in a thermostatic bath at $60 \pm$ $1^{\mathrm{o}} \mathrm{C}$ (the ethanol boiling point) for $10,20,30,50$, 60 and 120 min with intermediate shaking (Dubnoff Metabolic Shaking Incubator; GCA Corporation; Precision Scientic Group; USA, speed position 3); and then filtered (paper filter, pore diameter $=1 \mathrm{~mm})($ Experiment 2$)$. The recovered volume was registered.

\subsection{Extractions}

Extracts of maté leaves for the experimental design were prepared in duplicate according to Experiment 2, as described in section 2.5, but using solutions with different ethanol concentrations (Table 1) and an extraction time of $30 \mathrm{~min}$.

Three additional extractions were performed in duplicate: Experiment 12 (similar to Experiment 2 but at $95 \pm 2^{\circ} \mathrm{C}$ ) in order to investigate a possible effect of temperature on the recovery of polyphenols in aqueous extraction; Experiment 13 (similar to Experiment 10 but using $X_{2}=40$ ), which was conducted to validate the polynomial model and Experiment 14 (similar to Experiment 10 but using $X_{2}=96$; based on overlapping contour plots for each response) in order to check if a $96 \% \mathrm{v} / \mathrm{v}$ aqueous ethanol solution reduced the solubility of total polyphenols present in maté leaves.

All the extracts were filtered (paper filter, pore diameter $=1 \mathrm{~mm}$ ) and their recovered volumes were registered. They were stored at $-21^{\circ} \mathrm{C}$ until all analytical tests were performed. Before testing, each extract was heated to room temperature, centrifuged for $5 \mathrm{~min}$ and diluted with distilled water $1: 5 ; 1: 8$ or $1: 9$ and then diluted 
again to 1:100 for TPC analysis; and between 1:50-1:200 for the AOC and CC analyses.

\subsection{Determination of total polyphenols content}

The TPC was determined by the Folin-Ciocalteu method (ISO 14502-1, 2004) and it was expressed as chlorogenic acid equivalents (CAE) in $\mathrm{g}(100$ $\mathrm{g} \mathrm{dm})^{-1}$ (g CAE \% dm). One milliliter of the diluted sample extract was transferred in duplicate to separated tubes containing $5.0 \mathrm{~mL}$ of water diluted Folin-Ciocalteu's reagent $\left(10 \% \mathrm{v} \mathrm{v}^{-1}\right)$. Then, $4.0 \mathrm{~mL}$ of a sodium carbonate solution $\left(7.5 \% \mathrm{w} \mathrm{v}^{-1}\right)$ was added. The tubes were then kept at room temperature for $60 \mathrm{~min}$ and the absorbance was measured at $765 \mathrm{~nm}$.

The concentration of polyphenols in each sample was calculated from a standard curve of chlorogenic acid ranging from 0 to $50 \mu \mathrm{g} \mathrm{mL}{ }^{-1}\left(\mathrm{R}^{2}=\right.$ 0.9995). The concentration of total polyphenols in the original extracts (TPCo) was expressed as $\mu \mathrm{g} \mathrm{CAE} \mathrm{mL}^{-1}$.

\subsection{Caffeine content}

Caffeine content (CC) was determined using an HPLC technique (IRAM 20512, 2003). A C18 column (Ultrasphere; $250 \mathrm{~mm} \times 4.6 \mathrm{~mm}$., Beckman. USA) with a particle diameter of $5 \mu \mathrm{m}$, a mobile phase of methanol:water $\left(30: 70 \mathrm{v} \mathrm{v}^{-1}\right)$ at

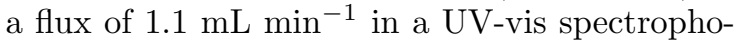
tometer (Waters model 481) and a wavelength of $280 \mathrm{~nm}$ were used. Results were given in $\mathrm{g}$ caffeine $(100 \mathrm{~g} \mathrm{dm})^{-1}$ (g CC \% dm). Determinations were made in duplicate.

\subsection{DPPH radical scavenging}

The antioxidant activities of the extracts were determined as a measure of radical scavenging, using the DPPH radical assay described by Hartwig, Brumovsky, Fretes, and Sánchez Boado (2012a). In this method, $100 \mu \mathrm{L}$ of the aqueous dilution of the maté extracts was mixed with 3.0 $\mathrm{mL}$ of a DPPH solution in methanol $(100 \mu \mathrm{M})$. The mixture was incubated for 120 min in darkness at $37 \pm 1{ }^{\mathrm{o}} \mathrm{C}$, and then the absorbance was read at $517 \mathrm{~nm}$. For the blank probe, the $100 \mu \mathrm{L}$ of diluted maté extracts were replaced by $100 \mu \mathrm{L}$ of methanol.

The DPPH radical concentration in the reaction mixture at any time was estimated from the absorbance profile of the DPPH radical: $\mathrm{A}=0.0103$ $\mathrm{c}-0.0013\left(\mathrm{R}^{2}=1\right)$; where $\mathrm{c}$ is the concentration of DPPH radical $(\mu \mathrm{M})$ in the range $10-100$ $\mu \mathrm{M}$. In order to determine the absorbance profile of the $\mathrm{DPPH}$ radical, $100 \mu \mathrm{L}$ of methanol was mixed with $3.0 \mathrm{~mL}$ of a DPPH solution in methanol and the absorbance was read immediately in a dark room. The results of the assay were expressed as ascorbic acid equivalents and Trolox equivalents in $\mathrm{g}(100 \mathrm{~g} \mathrm{dm})^{-1}(\mathrm{~g} \mathrm{AAE}$ $\% \mathrm{dm}$ and $\mathrm{g} \mathrm{TE} \% \mathrm{dm})$. They were calculated as the percentage of residual DPPH radical remaining at the steady state (DPPHre) according to 6 , where DPPHss is the concentration of radical DPPH at the steady-state and DPPHo is the initial concentration expressed in $\mu \mathrm{M}$.

$$
\text { DPPHre }=\text { DPPHss } \frac{100}{\text { DPPHo }}
$$

The concentration of ascorbic acid and Trolox standards were derived from the following standard curves ranging from 0 to $1.2 \mathrm{mM}, \mathrm{y}=$ $3.9808 \mathrm{x}+99.996\left(\mathrm{R}^{2}=0.9984\right)$ and $\mathrm{y}=-2.7675$ $\mathrm{x}+99.054\left(\mathrm{R}^{2}=0.9991\right)$ respectively, where $\mathrm{y}$ is DPPHre and $\mathrm{x}$ is the amount of the standard used in the reaction ( $\mu \mathrm{g}$ of standard).

\section{$2.10 \quad$ Statistical analysis}

Response surface methodology, Pearson's Correlation technique and Student's t-test were used to analyze the experimental data within Statgraphics Centurion XVI Académico. Data was expressed as mean \pm standard error.

\section{Results and discussion}

\subsection{Preliminary experiments}

There were significant differences $(\mathrm{p} \leq 0.012)$ between the TPC of twigs and leaves. The TPC in twigs was $36 \%$ lower than the TPC in leaves $(14.1 \pm 1.24$ vs $22.2 \pm 0.14 \mathrm{~g}$ CAE $\%$ dm respectively); so leaves were chosen as the test material for extractions. Differences between both 
fractions may be explained by differences in the composition and functions of twig and leave tissues. Metabolic functions take place in leaves whilst twigs serve circulation and transport purposes. Holovatty, Argüello, and Malee (2006) reported total polyphenols contents of $17.3 \pm 0.3$ and $6.6 \pm 0.1 \mathrm{~g} \mathrm{CAE} \mathrm{\%} \mathrm{dm} \mathrm{for} \mathrm{maté} \mathrm{leaves} \mathrm{and}$ twigs respectively. The differences between these values and those reported in this research may be attributed, among other factors, to the lack of standardization in extraction conditions and the applied analytical methodology. The TPC of the methanolic extract (Experiment 1) obtained from the maté leaves was considered as the maximum TPC possible to achieve and this extraction system was considered as the control extraction for the experimental design extractions from maté leaves.

The aqueous extraction curve (Fig 1) from Experiment 2 (water, $60{ }^{\circ} \mathrm{C}, 30 \mathrm{~min}$ ) showed an increase in the extraction yield with time. A high initial rate of polyphenols' extraction, followed by a slower extraction rate and an asymptotic approach to the equilibrium content, were observed. In the first 10 and $20 \mathrm{~min}$, an extraction percentage of $69 \%$ and $82 \%$ of the final TPC were respectively achieved. The aqueous extraction at $60^{\circ} \mathrm{C}$ reached the plateu at approximately $30 \mathrm{~min}$, with an equilibrium TPC equal to 11.3 $\pm 0.18 \mathrm{~g} \mathrm{CAE} \% \mathrm{dm}$.

Based on results obtained in Experiment 1 and 2 , the extraction system used in Experiment 2 (water, $60^{\circ} \mathrm{C}, 30 \mathrm{~min}$ ) was considered as less effective because it used water at a relatively low extraction temperature. Consequently in all the following experiments, an extraction time of 30 min was employed.

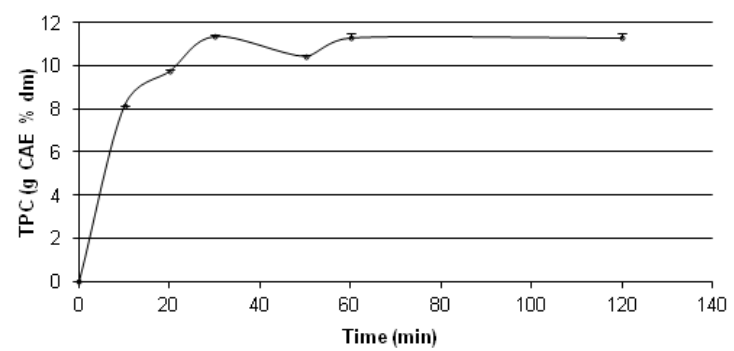

Figure 1: Aqueous extraction curve of TPC from maté leaves at $60^{\circ} \mathrm{C}$.

\subsection{Response surface analysis}

Response surface design and corresponding experimental data, under different extraction conditions, are shown in Table 1 , while Table 2 summarizes the regression coefficients and the criteria used to evaluate the fit of the response surface.

Only predicted data for TPC and AOC extraction gave good agreement with experimental values $\left(\mathrm{R}^{2}>90 \%\right.$ and MPE $<4.9$ (see Fig. 2). There was poor agreement between data predicted by the models for TPCo and CC responses and experimental ones $\left(\mathrm{R}^{2}<80 \%\right.$ and MPE $>4.7)$. In all models, linear regression coefficients $\left(a_{1}\right.$ and $\left.a_{2}\right)$ were positive indicating that increases in all independent variables could favor recovery of total polyphenols and increased antioxidant capacity. The quadratic coefficient $\mathrm{a}_{11}$ was negligible in all responses, whereas the negative value of a22 gave a maximum value for the equation in all the responses (on about $X_{2}=40$ to $60 \%$ ). The interaction coefficient $\mathrm{a}_{12}$ was also negligible and all curves were parallel at all $X_{1}$ and $X_{2}$ values (see Fig. 2).

There is a reverse relation between the concentration of total polyphenols and total polyphenol contents in some cases, even if the liquid to solid ratios are the same (Exp 3 and 4$)$. This can be explained by the existence of maximum values in these responses between 40 and $60 \% \mathrm{w} \mathrm{w}^{-1}$ for $X_{2}$ (see Fig. 2).

The experimental value of the central point for TPCo was $42.9 \mu \mathrm{g} \mathrm{CAE} \mathrm{mL}^{-1}$ and it was also the maximum predicted value. According to the contour plots (not shown), the predicted values and the optimal conditions for each response are presented in Table 3.

The TPC $(11.3 \pm 0.18$ g CAE $\% \mathrm{dm})$ obtained in Experiment 2 (water, $60^{\circ} \mathrm{C}, 30 \mathrm{~min}$ ) represents around $51 \%$ of the maximum achievable TPC (Experiment 1). The highest experimental TPC from the experimental design was 13.4 $\pm 0.40 \mathrm{~g} \mathrm{CAE} \% \mathrm{dm}$ (Experiment 5 ), and it represents around $60 \%$ of the maximum achievable TPC (Experiment 1).

Hartwig, Brumovsky, and Fretes (2012b), when adding $200 \mathrm{~mL}$ of boiling water to a $3 \mathrm{~g}$ matétea bag for $5 \mathrm{~min}$, reported a TPC $12.6 \%$ lower $(19.40 \pm 0.38 \mathrm{~g} \mathrm{CAE} \% \mathrm{dm})$ than the value ob- 
$76 \mid$ Hartwig et al.

Table 2: Regression coefficients of significant terms and statistical parameters for the strength of the fit of the second order polynomial models of total polyphenols concentration (TPCo); total polyphenols content (TPC); Caffeine content (CC) and antioxidant capacity (AOC) for ethanolic extracts of maté leaves.

\begin{tabular}{|l|c|c|c|c|c|}
\hline Coefficient & TPCo & TPC & CC & \multicolumn{2}{|c|}{ AOC } \\
\cline { 5 - 6 } & & & & AOC-TE & AOC-AAE \\
\hline $\mathrm{a}_{0}$ & -72.540 & -7.900 & -0.394 & -17.984 & -12.633 \\
\hline Linear & 22.624 & 3.142 & 0.144 & 6.775 & 4.793 \\
\hline $\mathrm{a}_{1}$ & 1.391 & 0.293 & 0.006 & 0.521 & 0.365 \\
\hline $\mathrm{a}_{2}$ & \multicolumn{5}{|l|}{} \\
\hline Quadratic & -1.277 & -0.149 & -0.006 & -0.331 & -0.235 \\
\hline $\mathrm{a}_{11}$ & -0.009 & -0.003 & 0.0000 & -0.005 & -0.004 \\
\hline $\mathrm{a}_{22}$ & \multicolumn{5}{|l|}{} \\
\hline Crossproduct & -0.075 & -0.005 & 0.000 & -0.015 & -0.010 \\
\hline $\mathrm{a}_{12}$ & 79.53 & 91.46 & 78.38 & 89.94 & 90.27 \\
\hline $\mathrm{R}^{2}(\%)$ & 15.82 & 0.49 & 0 & 0.92 & 1.85 \\
\hline$\chi^{2}$ & 13.042 & 2.402 & 0.085 & 3.129 & 4.453 \\
\hline $\mathrm{RSME}$ & 8.090 & 4.446 & 4.772 & 4.856 & 4.881 \\
\hline MPE &
\end{tabular}

Regression coefficients of significant terms, the coefficient of determination (R2), CHIsquare $\left(\chi^{2}\right)$, the Root square mean error (RSME) and the Mean percent error (MPE) of the quadratic polynomial models for the responses: TPCo (gCAE/100 $\mathrm{mL}) ; \mathrm{TPC}(\mathrm{g} \mathrm{CAE} \mathrm{\%} \mathrm{dm);} \mathrm{CC(g} \mathrm{CAF} \mathrm{\%} \mathrm{dm);} \mathrm{AOC} \mathrm{(g} \mathrm{TE} \mathrm{\%} \mathrm{dm} \mathrm{and} \mathrm{g} \mathrm{AAE} \mathrm{\%} \mathrm{dm).}$

Table 3: Predicted maximum values for each response (TPCo: Concentration of total polyphenols, TPC: Total polyphenols content, CC: Caffeine content and AOC: antioxidant capacity) and their optimal conditions for the ethanolic extraction with $\mathrm{X}_{1}$ (g liquid/g dry solid) and $\mathrm{X}_{2}$ (ethanol concentration, in $\% \mathrm{w} / \mathrm{w})$

\begin{tabular}{|l|l|l|l|}
\hline Response & Predicted values & \multicolumn{2}{|l|}{ Optimal conditions } \\
\cline { 3 - 4 } & & $\mathbf{X}_{1}$ & $\mathbf{X}_{2}$ \\
\hline TPCo & 40 & $5.7-9.4$ & $22-66$ \\
\hline TPC & 13 & $8-11.8$ & $27-53$ \\
\hline AOC & $22(\mathrm{TE})$ and $15.5(\mathrm{EAA})$ & $7.3-11.5$ & $19-54$ \\
\hline CC & 0.42 & $8-12.3$ & $19-55$ \\
\hline
\end{tabular}

TPCo (g CAE/100 mL); TPC (g CAE \% dm); CC (g CAF \% dm); AOC (g TE \% dm and g AAE \% dm); CAE: chlorogenic acid equivalents; AAE: ascorbic acid equivalents; TE: Trolox equivalents; CC: caffeine content; dm: dry matter.). 

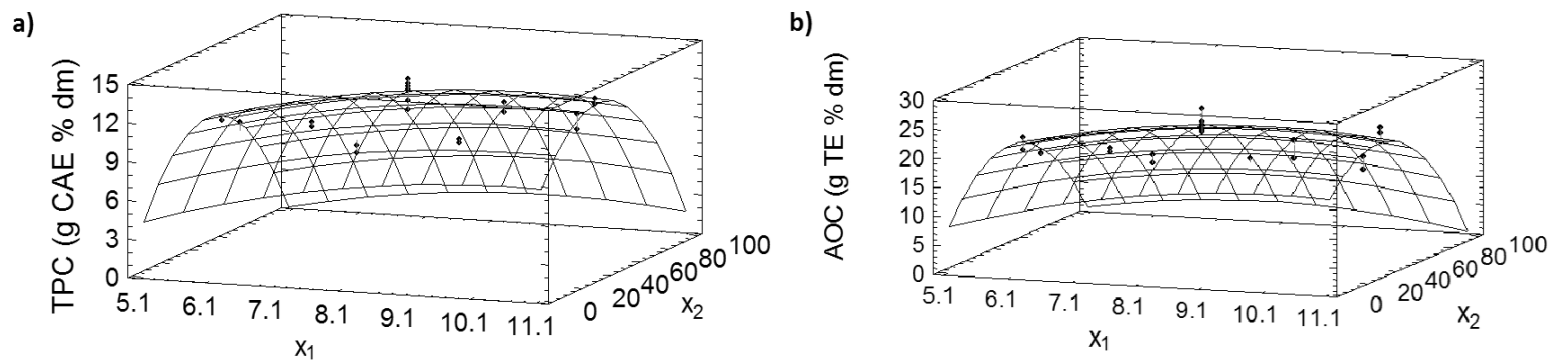

Figure 2: Response surfaces for the effects of liquid to solid ratio $\left(\mathrm{X}_{1}\right.$, weight basis) and solvent composition $\left(\mathrm{X}_{2}\right.$, weight basis) on total polyphenols content (a) and antioxidant capacity (b) of maté leaves.

served as the maximum achieveable TPC (Experiment 1).

The results indicate that the highest TPC could be achieved using a liquid to solid ratio and an ethanol concentration from 8 to 11 and 20 to $50 \% \mathrm{w} \mathrm{w}^{-1}$ respectively. An increase in the ethanol concentration beyond approximately $55 \%$ significantly contributed to a decrease in the extractability of total polyphenols from maté leaves. The results are in accordance with the data in Table 2, which showed that the interactive coefficient of ethanol concentration with liquid to solid ratio in the TPC was very low.

Turkmen et al. (2006) applied successive extractions using $50 \%$ and $80 \%$ aqueous ethanol solutions and reported a TPC of $10.61 \mathrm{~g}$ galic acid equivalents (GAE) \% dm (10.1 $\pm 3.24 \mathrm{mg}$ GAE $(\mathrm{g} \mathrm{dm})^{-1}$, as published) and $8.35 \mathrm{~g} \mathrm{GAE} \% \mathrm{dm}$ (83.5 $\mathrm{mg}$ GAE $(\mathrm{g} \mathrm{dm})^{-1}$, as published), respectively. Our results indicate that an increase in solvent polarity contributes to an increase in the solubility of total polyphenols present in maté leaves.

The overlap of the maximum zones for each response gave an optimal range for the extraction of phenolics from maté leaves of $8 \leq \mathrm{X}_{1} \leq 9$ and $30 \leq \mathrm{X}_{2} \leq 50$ at $60{ }^{\circ} \mathrm{C}$ for $30 \mathrm{~min}$.

\subsection{Additional extraction experiments}

The results of the additional extraction experiments (Experiments 12-14) are presented in Table 4. Experimental values for Experiment 13 were close to the predicted ones, confirming the validity and adequacy of the predicted models for TPC and AOC.

Although the total polyphenol extraction yield, using boiling water and $\mathrm{X}_{1}=8 \mathrm{~g}$ liquid $(\mathrm{g} \mathrm{dm})^{-1}$ (Experiment 12; Table 4), is reasonably close to the extraction yield using ethanolic extraction $\left(40 \% \mathrm{w} \mathrm{w}^{-1}\right)$ with the same value of $\mathrm{X}_{1}$ (Experiment 13), the AOC value was higher in the first case. Pagliosa et al. (2010), using the DPPH method, reported an antioxidant capacity of aqueous extract from maté leaves which was 1.1 order of magnitude higher than the values observed for methanolic leaf extract. According to Turkmen et al. (2006), extracts obtained using high polarity solvents are considerably more effective radical scavengers than those using low polarity solvents, indicating that antioxidants or active compounds with different polarities could be present in maté extracts.

Using ethanol as solvent (Experiment 14), the extraction of phenolic compounds was 6.4 and 5.3 orders of magnitude lower than the extraction obtained in Experiments 12 and 13 respectively, which is in accordance with the findings of other authors Jokić et al. (2010), Turkmen et al. (2006). This is probably because the polyphenolic compounds with hydroxyl groups in their chemical structure are hydrophilic, and so they are generally more soluble in water-ethanol solutions than in pure ethanol.

Ethanol is a bio-solvent that can be generated through fermentation of several sugar- or starchcontaining raw materials, with the possibility of recycling. Thus its use can be a basic element for the development of a sustainable process. Aqueous extraction is considered as a green extraction; 
Table 4: Experimental data of TPC, AOC-TE and AOC-AAE extracted from maté leaves obtained in additional extraction experiments

\begin{tabular}{|l|l|l|l|}
\hline Experiment & TPC & AOC-TE & AOC-AAE \\
\hline 12 & $12.25 \pm 0.16^{a}$ & $26.9 \pm 0.4^{a}$ & $19.0 \pm 0.3^{a}$ \\
\hline 13 & $12.33 \pm 1.35^{a}$ & $22.5 \pm 2.8^{b}$ & $16.0 \pm 1.9^{b}$ \\
\hline 14 & $2.85 \pm 0.10^{b}$ & $4.2 \pm 0.2^{c}$ & $3.1 \pm 0.2^{c}$ \\
\hline
\end{tabular}

Data are expressed as means $\pm \mathrm{SE}$. Values bearing different letters are significantly different at $\mathrm{p} \leq 0.012$

TPC: Total polyphenols content (gCAE \%dm); AOC-TE: antioxidant capacity (gTE \%dm); AOC-AAE: antioxidant capacity (g AAE \%dm); CAE: chlorogenic acid equivalents; AAE: ascorbic acid equivalents; TE: Trolox equivalents; dm: dry matter

its main drawback is the low yield in antioxidants with low polarity or liposoluble antioxidants; and such compounds do not represent the main antioxidant compounds present in maté.

Although the highest extraction efficiency was obtained using an aqueous methanol solution (Experiment 1), aqueous and ethanol solutions have been shown as efficient for the extraction of phenolic compounds from maté leaves and furthermore, they present the competitive advantage of abundance and low toxicity, respectively. Finally, considering its use in food and nutraceuticals, aqueous plant extracts are nutritionally more relevant and have advantages in relation to certification and safety so boiling water extraction is recommended (Experiment 12).

\section{Conclusions}

Maté leaves were selected as the test material because they have a $36 \%$ higher total polyphenols content (TPC) than the twigs. The extraction yield and the antioxidant capacity of the extracts from maté were highly dependent on the solvent polarity, which determines both qualitatively and quantitatively the extracted antioxidant compounds.

Aqueous ethanol solutions, in the range of 30-50 $\% \mathrm{w} \mathrm{w}^{-1}$ concentrations with liquid to solid ratios ranging from 8 to $9 \mathrm{~g}$ liquid $(\mathrm{g} \mathrm{dm})^{-1}$ for $30 \mathrm{~min}$ at $60 \pm 1^{\mathrm{O}} \mathrm{C}$ were found to be as effective in extracting polyphenol compounds from the leaves of maté, as boiling water for the same extraction time and the same liquid to solid ratio. The optimal results for total polyphenols content were lower than the previously reported values for $70 \%$ methanol extraction (Experiment 1), but both boiling water and aqueous ethanol would be suitable to replace methanol for a food grade and more environmentally friendly solid-liquid extraction.

\section{Acknowledgements}

We thank the National Council of Scientific and Technical Research (CONICET) and National Institute of Yerba Mate (INYM) for their financial support of this work, and the National University of Misiones and DINCYT Foundation for the use of their laboratory equipment.

\section{References}

Astill, C, Birch, M., Dacombe, C, Humphrey, P., \& Martin, P. (2001). Factors affecting the caffeine and polyphenol contents of black and green tea infusions. Journal of Agricultural and Food Chemistry, 49(11), 53405347. doi:10.1021/jf010759+

Bravo, L., Goya, L., \& Lecumberri, E. (2007). LC/MS characterization of phenolic constituents of mate (Ilex paraguariensis, St. Hil.) and its antioxidant activity compared to commonly consumed beverages. Food Research International, 40(3), 393405. doi:10.1016/j.foodres.2006.10.016

Cacace, J., \& Mazza, G. (2003). Optimization of extraction of anthocyanins from black currants with aqueous ethanol. Journal of 
Polyphenol extraction from maté $\mid 79$

Food Science, 68(1), 240-248. doi:10.1111/ j.1365-2621.2003.tb14146.x

Dudonné, S., Vitrac, X., Coutiere, P., Woillez, M., \& Merillon, J.-M. (2009). Comparative Study of Antioxidant Properties and Total Phenolic Content of 30 Plant Extracts of Industrial Interest Using DPPH, ABTS, FRAP, SOD, and ORAC Assays. Journal of Agricultural and Food Chemistry, 57(5), 1768-1774. doi:10.1021/jf803011r

Filip, R, Lotito, S., Ferraro, G, \& Fraga, C. (2000). Antioxidant activity of Ilex paraguariensis and related species. Nutrition Research, 20(10), 1437-1446. doi:10 . 1016/S0271-5317(00)80024-X

Hartwig, V. G., Brumovsky, L. A., Fretes, R. M., \& Sánchez Boado, L. (2012a). A novel procedure to measure the antioxidant capacity of Yerba maté extracts. Ciência e Tecnologia de Alimentos, 32, 126-133. doi:\{10. 1590/S0101-20612012005000022\}

Hartwig, V., Brumovsky, L., \& Fretes, M. (2012b). A total polyphenol content of mate (Ilex paraguariensis) and other plants-derived beverages. Journal of Food Research, 1(3), 58-66. doi:10.5539/jfr . v1n3p58

Hayouni, E. A., Abedrabba, M., Bouix, M., \& Hamdi, M. (2007). The effects of solvents and extraction method on the phenolic contents and biological activities in vitro of Tunisian Quercus coccifera L. and Juniperus phoenicea L. fruit extracts. Food Chemistry, 105(3), 1126-1134. doi:10.1016/j . foodchem.2007.02.010

Holovatty, S, Argüello, B, \& Malee, L. (2006). Variación del contenido de polifenoles durante el procesamiento de yerba mate (Ilex paraguariensis). In Proceedings of $4^{t h}$ South American Congress of Yerba Maté. Posadas. Argentina. From 5 to 8 November 2006. ISBN 987-23223-0-9, 127-131.

IRAM 20512. (2003). Argentine Institute of Standardization and Certification -Yerba mate: Determination of caffeine content. Accessed: January 22, 2013. Retrieved from http://www.iram.org.ar

ISO/FDIS 14502-1:2004. (2004). Determination of total polyphenols in tea - Colorimetric method using Folin-Ciocalteu reagent.
Part 1. Accessed: January 22, 2013. Retrieved from http:// www.iso.org / iso / home/store/catalogue_tc/catalogue_detail. htm? csnumber $=31356 \backslash \&$ commid $=47858$

Jokić, S., Velić, D., Bilić, M., Bucić-Kojić, A., Planinić, M., \& Tomas, S. (2010). Modelling of the Process of Solid-Liquid Extraction of Total Polyphenols from Soybeans. Czech Journal of Food Sciences, 28(3), 206-212.

Khokhar, S, \& Magnusdottir, S. (2002). Total phenol, catechin, and caffeine contents of teas commonly consumed in the United Kingdom. Journal of Agricultural and Food Chemistry, 50(3), 565-570. doi:10.1021/ jf0101531

Lapornik, B, Prosek, M, \& Wondra, A. (2005). Comparison of extracts prepared from plant by-products using different solvents and extraction time. Journal of Food Engineering, 71(2), 214-222. doi:10.1016/j. jfoodeng.2004.10.036

Pagliosa, C. M., Vieira, M. A., Podesta, R., Maraschin, M., Bertello Zeni, A. L., Amante, E. R., \& de Mello Castanho Amboni, R. D. (2010). Methylxanthines, phenolic composition, and antioxidant activity of bark from residues from mate tree harvesting (Ilex paraguariensis A. St. Hil.) Food Chemistry, 122(1), 173-178. doi:10. 1016/j.foodchem.2010.02.040

Pineda Rivelli, D, Vitoriano Da Silva, V, Dislich Ropke, C, Varella, D, Leite Almeida, R, Higashi Sawada, T, \& Berlanga de Moraes Barros, S. (2007). Simultaneous determination of chlorogenic acid, caffeic acid and caffeine in hydroalcoholic and aqueous extracts of Ilex paraguariensis by HPLC and correlation with antioxidant capacity of the extracts by DPPH reduction. Brazilian Journal of Pharmaceutical Sciences, 43(2), 215-222.

Ramallo, L. A., Lovera, N. N., \& Schmalko, M. E. (2010). Effect of the application of intermittent drying on Ilex paraguariensis quality and drying kinetics. Journal of Food Engineering, 97(2), 188-193. doi:10.1016/j. jfoodeng.2009.10.008

Rostagno, M., Palma, M, \& Barroso, C. (2004). Pressurized liquid extraction of isoflavones 
from soybeans. Analytica Chimica Acta, 522(2), 169-177. doi:10.1016/j.aca.2004. 05.078

Sairro, S. T., Gosmann, G., Saffi, J., Presser, M., Richter, M. F., \& Bergold, A. M. (2007). Characterization of the constituents and antioxidant activity of Brazilian green tea (Camellia sinensis var. assamica IAC-259 cultivar) extracts. Journal of Agricultural and Food Chemistry, 55(23), 9409-9414. doi:10.1021/jf071796p

Sambiassi, C, Escalada, A., \& Schmalko, M. (2002). Extraction optimization of soluble compounds of yerba mate. Brazilian Archives of Biology and Technology, 45(2), 189-193.

Santos, D. T., Veggi, P. C., \& Meireles, M. A. A. (2012). Optimization and economic evaluation of pressurized liquid extraction of phenolic compounds from jabuticaba skins. Journal of Food Engineering, 108(3), 444452.

Spigno, G., Trarnelli, L., \& De Faveri, D. M. (2007). Effects of extraction time, temperature and solvent on concentration and antioxidant activity of grape marc phenolics. Journal of Food Engineering, 81(1), 200208. doi:10.1016/j.jfoodeng.2006.10.021

Turkmen, N, Sari, F, \& Velioglu, Y. (2006). Effects of extraction solvents on concentration and antioxidant activity of black and black mate tea polyphenols determined by ferrous tartrate and Folin-Ciocalteu methods. Food Chemistry, 99(4), 835-841. doi:10.1016/j.foodchem.2005.08.034

Wettasinghe, M, \& Shahidi, F. (1999). Evening primrose meal: A source of natural antioxidants and scavenger of hydrogen peroxide and oxygen-derived free radicals. Journal of Agricultural And Food Chemistry, 47(5), 1801-1812. doi:10.1021/jf9810416

Wijngaard, H. H., \& Brunton, N. (2010). The optimisation of solid-liquid extraction of antioxidants from apple pomace by response surface methodology. Journal of Food Engineering, 96(1), 134-140. doi:10.1016/j. jfoodeng.2009.07.010

Yao, L., Jiang, Y., Caffin, N, D'Arcy, B, Datta, N, Liu, X, .. Xu, Y. (2006). Phenolic compounds in tea from Australian super- markets. Food Chemistry, 96(4), 614-620. doi:10.1016/j.foodchem.2005.03.009

Zhou, K., \& Yu, L. (2004). Effects of extraction solvent on wheat bran antioxidant activity estimation. Lebensmittel-Wissenschaft Und-Technologie-Food Science and Technology, 37(7), 717-721. doi:10.1016/j.lwt. 2004.02.008 